CAUSATION

\title{
Children of parents with substance abuse disorders had higher rates of conduct disorder and substance use
}

\author{
Merikangas KR, Dierker LC, Szatmari P. Psychopathology among offspring of parents with substance abuse and/or anxiety \\ disorders: a high-risk study. J Child Psychol Psychiat 1998 Jul;39:711-20.
}

\section{Question}

Are parental substance abuse and anxiety disorders risk factors for psychopathology in offspring?

\section{Design}

Cohort study.

\section{Setting}

New Haven, Connecticut, USA

\section{Participants}

192 children (mean age 12 y, $51 \%$ boys) of 123 white parents (mean age 39 y). There were 77 children of 52 parents with substance abuse disorders, 58 children of 36 parents with anxiety disorders, and 57 children of 35 parents with no history of psychiatric disorders (control group parents). Parents were recruited from alcohol, drug, anxiety, and general treatment settings or by a random procedure. Exclusion criteria were organic mental impairment, schizoaffective disorder, or schizophrenia.

\section{Assessment of risk factors}

Both parents of each child were independently interviewed for substance abuse and anxiety disorders using the Schedule for Affective Disorders and Schizophrenia, modified to include criteria from the Diagnostic and Statistical Manual of Mental Disorders 3rd edition, revised.

\section{Main outcome measures}

Diagnoses of psychiatric disorders (modified Kiddie-Schedule for Affective Disorders and Schizophrenia) were assigned by a blinded psychologist who conducted interviews with the child and with the mother. Data on social adjustment and overall functioning (Child Global Assessment Scale, CGAS), smoking ( $\geqslant 1-2$ times/wk), drug use ( $\geqslant 1$ time), and alcohol use ( $\geqslant 1$ time) were also collected.

\section{Main results}

The table summarises the results. No group differences existed for anxiety or affective disorders in children. Children of parents with substance abuse disorders had higher rates of conduct disorder than children of parents with anxiety disorders or with no psychiatric history, and lower overall functioning scores than children of parents with no psychiatric history $(p<0.01)$. Children of parents with substance abuse disorders and children of parents with anxiety disorders had higher rates of smoking than children of parents with no psychiatric history. Rate of drug use was highest in children of parents with substance abuse disorders, lower in children of parents with anxiety disorders, and lowest in children of control group parents; and a similar non-significant trend was shown for the rate of alcohol use.

\section{Conclusion}

Children of parents with substance abuse disorders had higher rates of conduct disorder, smoking, and drug use and lower overall functioning than children of parents with no history of psychiatric disorders.

Rates of disorders, smoking, and drug use in children by parental history

\begin{tabular}{lllll}
\hline Diagnosis & $\begin{array}{l}\text { Parents with } \\
\text { substance abuse }\end{array}$ & $\begin{array}{l}\text { Parents with } \\
\text { anxiety disorders }\end{array}$ & $\begin{array}{l}\text { Control } \\
\text { parents }\end{array}$ & $p$ Value \\
\hline Anxiety disorders & $10.4 \%$ & $22.4 \%$ & $10.5 \%$ & $\mathrm{NS}^{*}$ \\
Affective disorders & $13.0 \%$ & $12.1 \%$ & $3.5 \%$ & $\mathrm{NS}^{*}$ \\
Conduct disorder & $15.6 \%$ & $5.2 \%$ & $0 \%$ & $\mathrm{p}<0.05$ \\
Smoking & $24.7 \%$ & $13.8 \%$ & $1.8 \%$ & $\mathrm{p}<0.001$ \\
Drug use & $14.3 \%$ & $8.6 \%$ & $0 \%$ & $\mathrm{p}<0.05$ \\
\hline
\end{tabular}

*NS $=$ not significant.

Source of funding: United States Public Health Service.

For correspondence:Dr K R Merikangas, Genetic Epidemiology Research Unit, Yale University School of Medicine, 40 Temple Street, New Haven, CT 06510, USA. Fax +12037649739.

\section{Commentary}

The findings of this study by Merikangas et al support those of previous studies. ${ }^{12}$ This study was ambitious because it compared children of parents with substance abuse, parents with anxiety disorders, and parents with no history of psychopathology. These wide comparisons increase the generalisability of the study. The small number of children at each age limits the ability to examine the effects of psychopathology at each developmental stage. The study strengths, however, include the use of both community and clinical samples and many direct and indirect data collection methods. The primary result, which suggests a familial aggregation towards similar patterns among children, is interesting although not unexpected. Merikan- gas et al view children as having temperamental inclinations towards certain types of behaviours. Although the knowledge on temperament is well established, ${ }^{3}$ it would have been useful to have viewed the results in the context of social learning theory. For example, children of parents who abuse substances may be more likely to have access to illicit drugs and alcohol. These children may also be more likely to learn that one way of dealing with stress is to use illicit substances.

This study supports a family based approach to treating adults with substance abuse or anxiety disorders and encourages assessment and preventative therapy for children. The effects of having parents with a history of psychopathology has been noted before, ${ }^{4}$ and this study confirms the degree to which children can be affected if their needs are neglected by parents and professionals.

\section{Laurence Baldwin, RMN, MA \\ Clinical Nurse Specialist \\ Central Nottinghamshire Healthcare \\ NHS Trust, Mansfield \\ Nottinghamshire, UK}

1 Downey G, Coyne JC. Psychol Bull 1990;108:50-76

2 Owings West M, Prinz RJ. Psychol Bull 1987; 102:204-18

3 Chess S, Thomas A. Temperament in clinical practice. New York: Guilford Press, 1986.

4 Gopfert M, Webster J, Seeman M. Parental psychiatric disorder: distressed parents and their families New York: Cambridge University Press, 1996. 